\title{
Sensitivity to copper deficiency of different cereals and strains of cereals
}

\author{
K. W. Smilde and Ch. H. Henkens \\ Institute for Soil Fertility, van Hallstraat 3, Groningen, The Netherlands; \\ Agricultural Advisory Officer for Matters relating to Soil and Manuring, Bovenweg 7, \\ Bennekom, The Netherlands
}

Received 21 February, 1967

\section{Summary}

The sensitivity to copper deficiency of various strains of wheat, oats, barley and rye was studied in pot experiments with a sandy soil deficient in copper. Judging from the responses of grain yield to copper application, sensitivity decreased in the order wheat, oats, rye. Barley had an intermediate position between wheat and oats. Rye proved rather insensitive to copper deficiency. There were also found to be significant differences in sensitivity between the wheat, oat and barley strains. In sensitive strains of oats and barley under conditions of copper deficiency a reduction in grain yield was accompanied by an increase in straw yield, caused by profuse tillering. This did not occur in wheat. Reduction in grain yield resulted from a decrease in the number of fully developed grains. It may be accompanied by a decrease in average grain weight, depending on the presence of void grains. The effect of copper application on the copper content of oat and wheat foliage generally decreased with plant age. Sensitivity to copper deficiency was not found to be related to copper content of foliage and straw.

By studying their yield response curves, as obtained in water culture at various copper concentrations, it appeared that different oat strains differ in copper requirement. Copper responses of sensitive oat strains relative to that of an insensitive strain proved larger in soil than in water culture, indicating a difference in releasing capacity of the roots between these types.

\section{Introduction}

Plant varieties and species may differ considerably as to their sensitivity to nutrient deficiencies and excesses. Comprehensive reviews are given by Millikan (1961) and Vose (1963). According to Mulder (1938) wheat, oats and barley are much more sensitive to copper deficiency than is rye. This can be attributed to differences in copper requirement as was concluded from the results of water culture experiments in which all copper was present in a form readily available to plants. This author also demonstrated that cereals differ in ability to extract copper from soil substrates in which copper was not readily available. This has practical consequences in fertilizer policy. In The Netherlands a level of at least 3 p.p.m. soil copper (extraction with $0.4 \mathrm{~N} \mathrm{HNO}_{3}$ ) for oats and 4 for wheat is recommended to obtain optimal yields 
(Henkens, 1961).

In the present work the responses to copper of various strains of oats, wheat, barley and rye were studied. Three experiments were performed in soil culture and one in water culture.

\section{Materials and methods}

The responses to copper of Marne, Civena, Nestor, Abed Minor, Gouden Regen II, Adelaar, Zege, Zandster and Zwarte President (oats) and of Peko, Carpo, Koga II, Blanka and van Hoek (spring wheat) were studied in a pot experiment in 1958. A copper deficient sandy soil containing 1.5 p.p.m. $\mathrm{Cu}^{1}$ from Valthe (Drente) was used. The pots were of the ordinary Mitscherlich type (volume $5.2 \mathrm{l}$ ) containing $6.5 \mathrm{~kg}$ of soil. Thirty plants were grown in each pot and watered with demineralized water, the moisture content of the soil being kept at approx. $60 \%$ of the water capacity. Six plants were removed when $20 \mathrm{~cm}$ long and another four at ear emergence and analysed for copper (sodiumdiethyldithiocarbamate method). All pots received a basal dressing of A.R. chemicals at the following levels: $2.28 \mathrm{~g} \mathrm{NH}_{4} \mathrm{NO}_{3}(0.80 \mathrm{~g} \mathrm{~N}), 1.67 \mathrm{~g}$ $\mathrm{K}_{2} \mathrm{HPO}_{4}\left(0.68 \mathrm{~g} \mathrm{P}_{2} \mathrm{O}_{5} ; 0.90 \mathrm{~g} \mathrm{~K}_{2} \mathrm{O}\right), 1.0 \mathrm{~g} \mathrm{MgSO}_{4} .7 \mathrm{H}_{2} \mathrm{O}(0.16 \mathrm{~g} \mathrm{MgO})$. The number of pots for each strain of oats and wheat was six, three of which remained untreated and three received $0.157 \mathrm{~g}$ of copper sulphate (equivalent to $\pm 50 \mathrm{~kg} / \mathrm{ha}$ ). After harvesting the mature crop average number of tillers (stalks) and grains, length of stalks (including panicles and ears) and dry weight of straw and grains per pot were determined. The weight of 1000 grains was calculated and the straw was analysed for copper.

Similary, in 1959 the sensitivity to copper deficiency of the following strains was studied: Marne, Abed Minor (oats); Peko, Koga II (spring wheat); Dea, Urania, Vinesco (winter barley); Balder, Piroline, Practon, Minerva, Herta, Agio, Union (spring barley); Petkuser, Dominant (winter rye) and Petkuser spring rye. For one strain (Marne oats) the effect of copper reserves in the seed on copprr response was investigated by using seeds from the plus and minus copper treatment of the 1958 experiment. Plants were only analysed for copper at the ' $20 \mathrm{~cm}$ stage'.

In 1960, the latter experiment was repeated on a smaller scale with Peko (spring wheat); Dea, Urania and Vinesco (winter barley); Agio (spring barley); Petkuser and Dominant (winter rye) and Petkuser spring rye. The pots received fresh basal dressings but copper was not applied again.

In a water culture experiment in 1962 the oat strains Marne, Zege and Zwarie President were grown in 1.21 polythene pots at copper levels of $0,0.01,0.02$ and 0.04 p.p.m. The treatments consisted of four pots with five plants in each pot. At the '20 cm stage' one plant was removed from each pot and analysed for copper. Glassdistilled demineralized water was used for preparing the nutrient solutions which contained the following concentrations of major and minor elements (except copper) in p.p.m.: $191 \mathrm{~N}, 38 \mathrm{P}, 113 \mathrm{~K}, 34 \mathrm{Mg}, 240 \mathrm{Ca}, 0.36 \mathrm{~B}, 0.37 \mathrm{Mn}, 0.13 \mathrm{Zn}, 0.04 \mathrm{Mo}$ and $5 \mathrm{Fe}$ (as Fe EDTA). The nutrient solutions were replaced once every two weeks. The $\mathrm{pH}$ varied from 6.0 to 6.3. After harvesting countings were made and weights determined as outlined above. Contrary to the soil culture experiments, the water culture experiment was performed in a glass-house to prevent contamination.

1 Extraction with $0.4 \mathrm{~N} \mathrm{HNO}_{3}$ (Henkens, 1961). 


\section{Results}

\section{8 experiment}

Oat strains. None of the oat strains showed an effect of copper on plant height and, therefore, the data are not included in Table 1.

From the analysis of variance it appeared that the effects of strain, copper treatment and their interaction were all highly significant (at 1\%). The Student-Newman-Keuls range test was applied to the yield increments, resulting from the copper treatment, to investigate whether the responses to copper of the strains were different. The following order of increasing response to copper, i.e. increasing sensitivity to copper deficiency, was found:

Zw. Pres. Civena Nestor Marne Adelaar Zandster A. Minor G. Regen Zege

Strains underlined by a joint line do no significantly differ from each other (at $5 \%$ ). The strain Zwarte (Black) President was least sensitive to copper deficiency its grain yield being hardly increased by application of copper. There were found to be varying degrees of sensitivity within the yellow (Civena, Gouden Regen) and white (Nestor. Marne, Adelaar, Zandster, A. Minor and Zege) types.

Copper deficient plants of sensitive strains (e.g. Zege, Gouden Regen) were characterized by low grain and high straw yields. This is caused by the production of many tillers which do not form mature panicles. Less sensitive strains (e.g. Civena, Nestor) and the insensitive Zwarte President did not show this profuse tillering and straw yields were somewhat depressed by copper deficiency. Grain weight (1000 grains) of sensitive strains was more influenced by copper treatment than that of insensitive strains. The former produced many glumes remaining empty of grain under conditions of copper deficiency.

Application of copper raised the copper content of foliage as was shown by analyses at various stages of plant development. The effect was most pronounced at the $20 \mathrm{~cm}$ stage, except for Marne and Civena, but gradually decreased as the plants grew older. Copper content decreased with plant age, but after ear emergence no further decrease occurred. Sensitivity to copper deficiency and copper content of foliage (straw) were not found to be directly related. In sensitive strains copper application decreased yield of straw and, consequently, the total quantity of copper present in it.

Wheat strains. The stalks of plants receiving copper were 10-24 cm (dependent on the strain) longer than those of untreated plants. The ears were also longer (Table 2). Wheat appeared to be more sensitive to copper deficiency than oats. Grain production of copper deficient plants failed largely in Koga II and completely in Peko, Carpo and Blanka. Statistical analysis showed that only the effect of copper treatment was significant. The copper treatment $\times$ strain interaction was not significant which means that the strains did not differ significantly in sensitivity.

Both grain and straw yields were adversely affected by copper deficiency. The number of grains was greatly reduced but their weight was hardly affected.

As with oats, application of copper generally increased copper content of wheat foliage. The effect tended to decrease with plant age, but there were some exceptions. Copper content decreased with plant age but after ear emergence no further decrease occurred. 

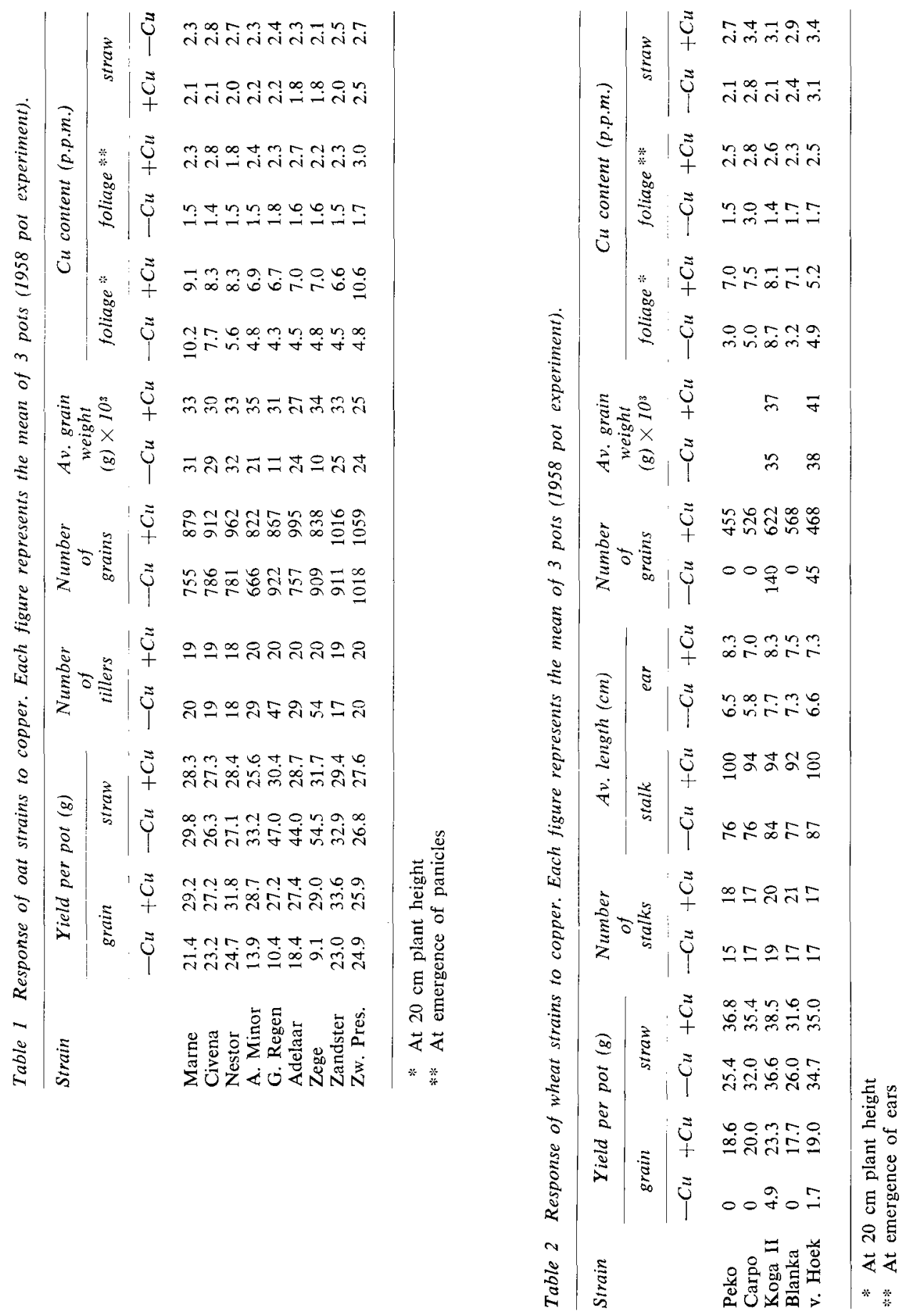


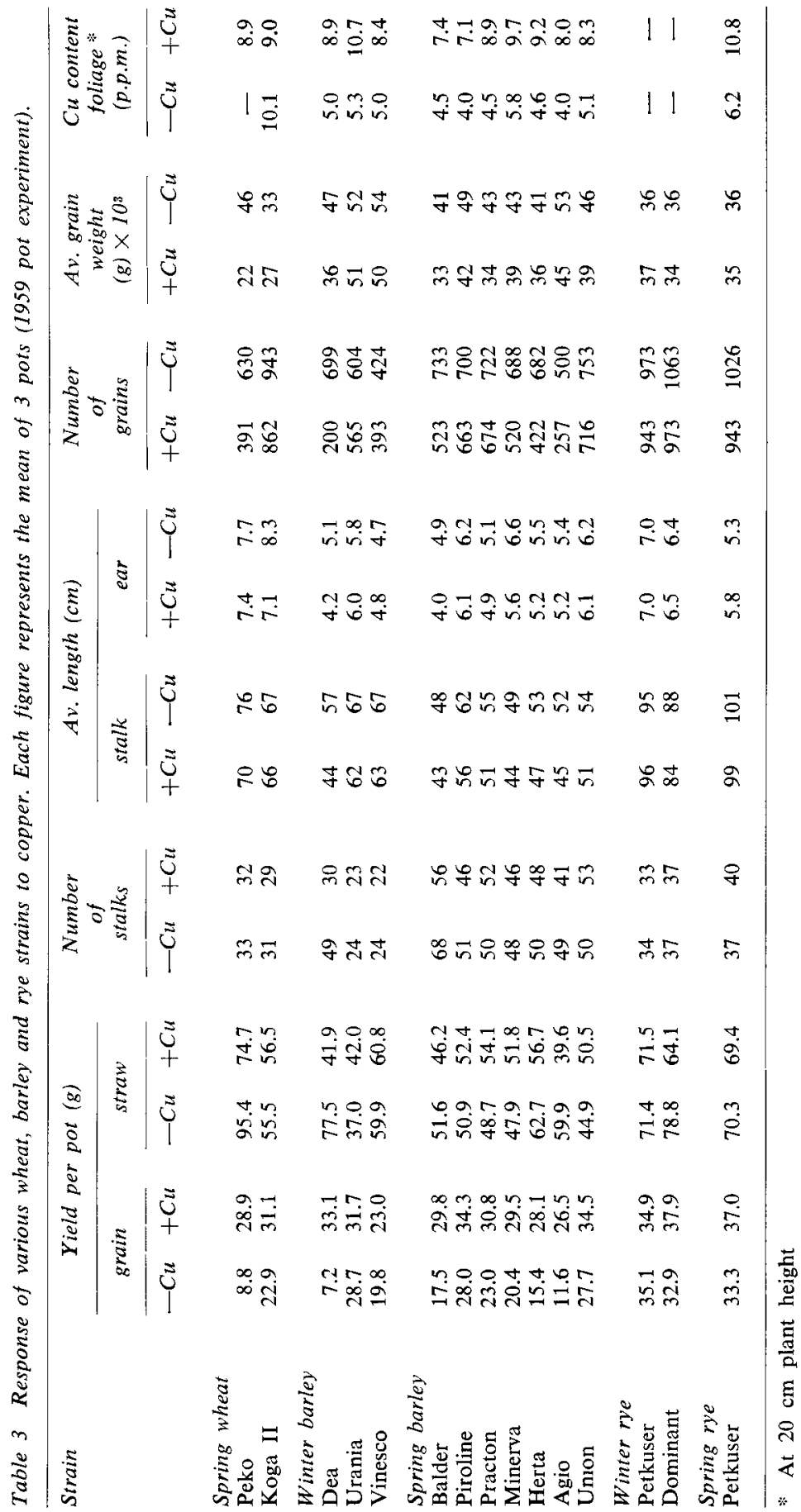




\section{9 experiment}

Oat strains. The results obtained with Marne and Abed Minor confirmed those of the previous experiment and are, therefore, not reported in Table 3. The Marne seeds used for sowing had been collected either from normal or from copper deficient plants in the 1958 experiment (cf. p. 250). This difference in origin of the seed did not affect copper response.

Wheat strains. There were some differences between the results of the 1958 and the 1959 experiment (cf. Table 2 and 3). Both straw and grain yields were considerably higher in the 1959 experiment, irrespective of copper treatment. The effects of strain and copper treatment were highly significant (at 1\%). As the interaction was also highly significant, in this experiment Peko clearly proved to be more sensitive to copper deficiency than Koga II. It is interesting to note that copper application reduced straw yield of Peko without affecting the number of stalks. Contrary to the results of the previous experiment, Koga II and Peko produced a large number of grains under conditions of copper deficiency. Judging trom the grain weight (1000 grains) many of these were not (fully) developed however; this holds especially for Peko.

Barley strains. Copper had a positive effect on average stalk length of winter barley, especially in Dea which also had longer ears. Statistical analysis showed that the effects of strain, copper treatment and their interaction were all highly significant at the $1 \%$ level. The significance of the copper effect is mainly caused by the large copper response of Dea. Grain yields of Urania and Vinesco were not significantly increased by application of copper. The behaviour of Dea as regards tillering is similar to that of sensitive oat strains (p. 251). Grain weight (1000 grains) of this sensitive strain was adversely affected by copper deficiency. On the other hand, tillering and grain weight of the insensitive strains Urania and Vinesco were only slightly influenced, whereas straw yields were somewhat depressed under these conditions. The copper treatment also increased average stalk length of spring barley. As shown by analysis of variance the effects of strain, copper nutrient and their interaction were all highly significant (at $1 \%$ ). With the range test (at $5 \%$ ), applied to the yield increments, the following order of increasing response to copper (i.e. increasing sensitivity to copper deficiency) was found:

Piroline Union Practon Minerva Balder Herta Agio

In the more sensitive strains (Agio, Herta, Balder) a decrease in grain yield was accompanied by an increase in straw yield (cf. Dea). In the less sensitive strains copper deficiency reduced both. Insufficient copper supply depressed grain weight (1000 grains) of both groups.

There was a distinct increase in copper content of the foliage of winter and spring barley (' $20 \mathrm{~cm}$ stage') following application of this nutrient. No close relationship between sensitivity to copper deficiency and copper content of foliage could be established.

Rye strains. Average stalk and ear length were not influenced by copper. According to the analysis of variance neither the nutrient effect nor the copper treatment $x$ strain interaction were significant. Copper tended to increase grain yield and to decrease straw yield somewhat in Dominant. 


\section{0 experiment}

The results largely confirm those of the 1959 experiment (Table 3) and need not be discussed here. As distinct from the latter, copper reduced straw yield in Dea winter barley without affecting the number of stalks; grain weight (1000 grains) was not increased. The data clearly demonstrate again the great difference in sensitivity to copper deficiency between wheat and rye.

\section{2 water culture experiment}

In this experiment the sensitivity to copper deficiency of some oat strains was tested. The results are recorded in Table 4.

The leaves of plants growing on nutrient solutions without copper showed distinct copper deficiency symptoms which were first noticed in Marne and Zege. The lowest level of copper supply ( 0.01 p.p.m.) proved adequate for Zwarte President to prevent deficiency symptoms but not for Marne and Zege. At higher copper concentrations the latter strains were seemingly healthy. Average stalk length was slightly increased by addition of copper to the nutrient solution.

Curves representing the response of grain yield to copper concentration of the substrate are given in Fig. 1. In the $0-0.01$ p.p.m. $\mathrm{Cu}$ range the trends are rather similar. At higher copper levels the curves diverge, the slope being largest for the curve representing Marne, nil for Zwarte President and intermediate for Zege. In other words, the copper requirement increased in the order Zwarte President, Zege, Marne. Zwarte President reached its maximum yield already at 0.01 p.p.m. $\mathrm{Cu}$. With increasing copper concentrations Marne and Zege produced an increasing number of fully developed grains. The average grain weights are low which is probably caused by the unfavourable climaticc conditions in the glass-house leading to mildew infection.

With increasing copper concentrations the total number of tillers decreased, but the proportion of stalks producing panicles increased. Many tillers were still green when the plants were harvested, especially at the lower copper levels. This was much more pronounced in Marne and Zege than in Zwarte President. Siraw yields showed no further increase at copper levels higher than 0.01 p.p.m. The number of stalks decreased at the highest copper concentration.

The total amount of copper in foliage (' $20 \mathrm{~cm}$ stage') increased with an increase in

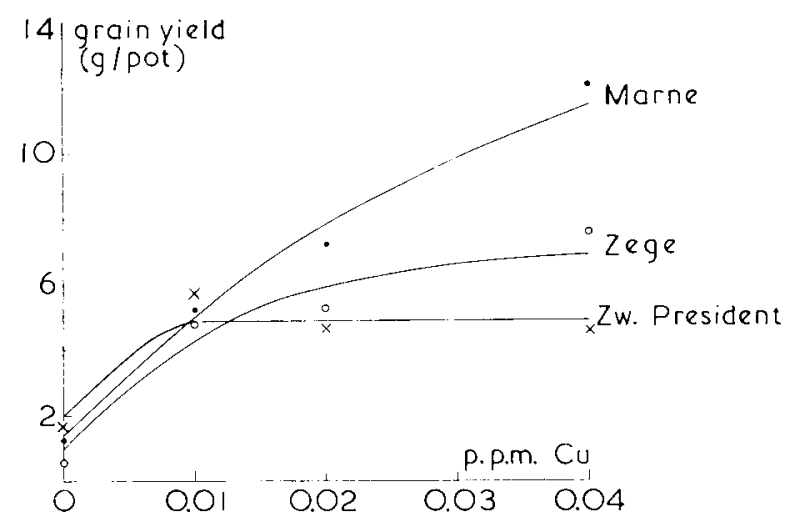

Fig. 1 Copper response of different oat strains in water culture (1962 experiment). 
K. W. SMILDE AND CH. H. HENKENS

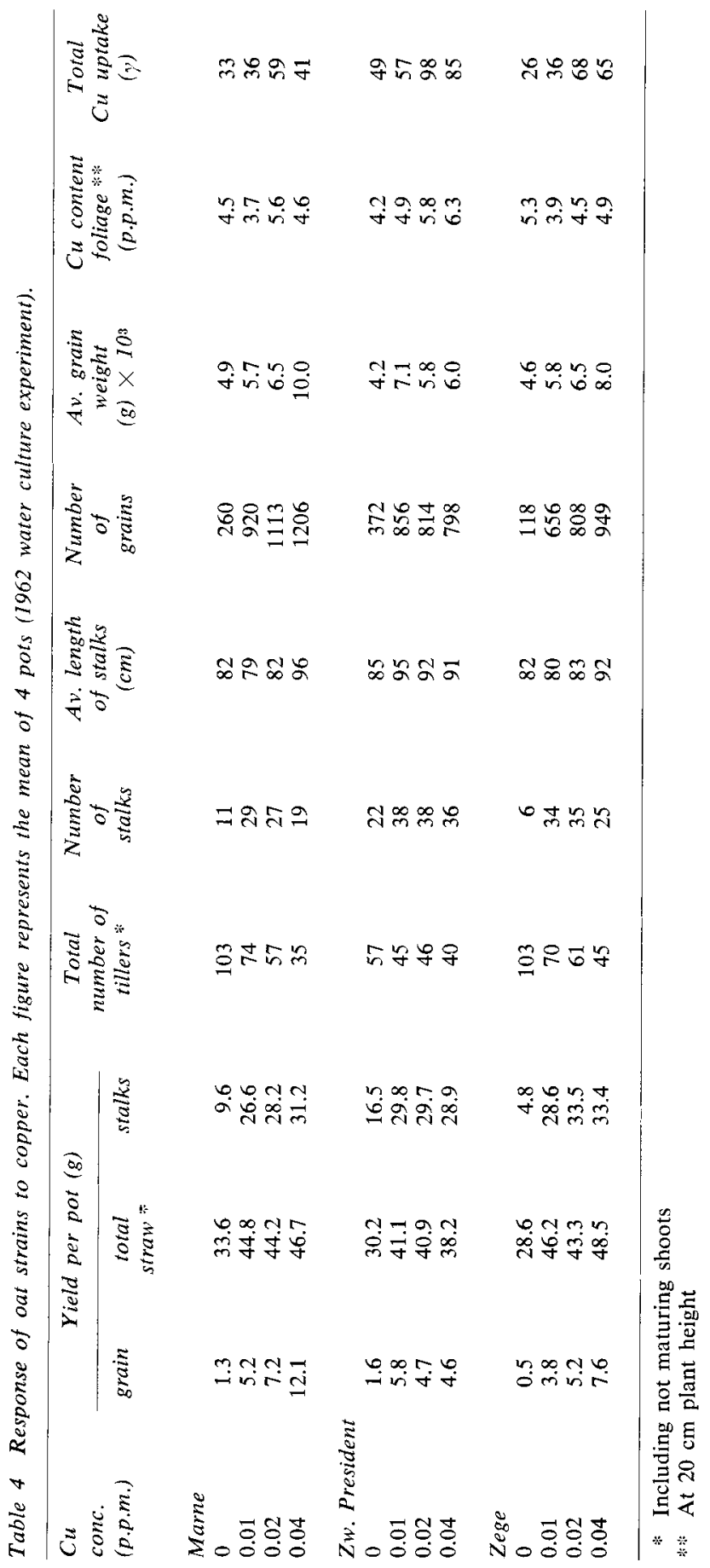


copper concentration of the nutrient solution up to a level of 0.02 p.p.m. A drop in copper content of foliage, probably due to dilution, occurred at 0.01 p.p.m. Cu in the nutrient solution. This was not found for Zwarte President.

\section{Discussion}

From the results it can be concluded that the sensitivity to copper deficiency decreases in the order wheat, oats, rye. Some strains of barley more resemble wheat than oats, for other strains the reverse is true. This was also found by Mulder (1938), Piper (1940), Harmer (1945), Nelson et al. (1956), Kannenberg (1959) and Pizer et al. (1966). However, not too great a value should be attached to the above classification. In a study by Mulqueen et al. (1961) oat strains proved more sensitive to copper deficiency than wheat strains.

In sensitive oat and barley strains copper deficiency manifested itself by a decrease in grain yield and profuse tillering (p. 251, 254). This was also observed by Brandenburg (1935), Mulder (1938), Piper (1942), Coppenet and Jolivet (1952), Hagin (1960), Scharrer and Schaumlöffel (1960) and Hey and Knabe (1964). The results obtained by Mulqueen et al. (1961) were also different in this respect.

Whether the depressing effect of copper deficiency on grain yield also leads to low average grain weights (1000 grains) depends on the number of void grains produced (see also Henkens and Smilde, 1966; Pizer et al., 1966).

The effect of copper application on the copper content of foliage of oat and wheat plants generally decreased with plant age. In our opinion it is not justified, therefore, to use a critical plant copper concentration ( 1 p.p.m.) at the flowering stage as a criterion for copper deficiency, as has been suggested by Piper and Walkley (1943). Mitchell et al. (1957) and Reith and Mitchell (1964) arrive at a similar conclusion. According to these authors soil-applied copper has little influence on the copper contents of straw and grains of oats. This was also shown in the present and in previous work (Henkens et al., 1965). In other words, the total amounts of copper in straw and grains increased (decreased) with an increase (decrease) in dry weight of these plant parts. Under conditions of copper deficiency most of the copper absorbed by strains sensitive to this disorder is, therefore, accumulated in the straw. Scharrer and Schaumlöffel (1960) state that oat plants are copper deficient if more than half of the total quantity of copper absorbed is present in the straw.

According to Mulder (1938) sensitivity to copper deficiency of cereals is governed both by the specific copper requirement and by the ability of the root system to release copper from the substrate. His conclusions are supported by Rademacher (1940) who tested the sensitivity of various oat strains. White strains were found to be more sensitive than black ones.

It can be seen in Table 5 that the difference in copper response (as expressed by the different yield increments) between Zwarte President and Zege was much greater in soil than in water culture. This can be attributed to different abilities of the root systems to extract copper from the soil. From the results it is not certain if this also holds for Zwarte President relative to Marne. In fact, the latter strain had not yet reached its maximum yield at a copper concentration of 0.04 p.p.m. in water culture. Furthermore, it is interesting that the copper response of Zege was larger than that of Marne in soil culture, whereas the reverse is true for water culture. It would appear, therefore, that Zege has a lower need for copper to attain a maximum yield than has Marne, but that its releasing capacity is also lower. 
Table 5 Response of grain yield (in $\mathrm{g}$ ) of oat strains to copper in soil and in water culture. Data taken from Table 1 and 4.

\begin{tabular}{|c|c|c|c|c|c|c|}
\hline \multirow[t]{2}{*}{ Strain } & \multicolumn{3}{|c|}{ Soil culture } & \multicolumn{3}{|c|}{ Water culture } \\
\hline & $-C u$ & $+C u$ & increment & $O C u$ & 0.04 p.p.m. Cu & increment \\
\hline Marne & 21.4 & 29.2 & 7.8 & 1.3 & 12.1 & 10.8 \\
\hline Zw. President & 24.9 & 25.9 & 1.0 & 1.6 & 4.6 & 3.0 \\
\hline Zege & 9.1 & 29.0 & 19.9 & 0.5 & 7.6 & 7.1 \\
\hline
\end{tabular}

\section{References}

Brandenburg, E., 1935. Ontginningsziekte en kopergebrek. Mededel. Inst. Suikerbietenteelt, 5 : 245256.

Coppenet, M. et Jolivet, E., 1952. Détection de graves carences en cuivre dans les terres très humifères du centre de la Bretagne. Compt. Rend. Acad. Agr. France, 38: 691-693.

Hagin, M., 1960. Wachstums- und Entwicklungsstörungen durch Kupfermangel bei Hafer. Z. Pflanzenernähr., Düng., Bodenk., $90: 37-50$.

Harmer, P. M., 1945. Studies on the effect of copper sulphate applied to organic soils on the yield and quality of several crops. Soil Sci. Soc. Am. Proc., $10: 284-294$.

Henkens, Ch. H., 1961. Koperbepalingen op bouwland. De waarde van chemische bepalingsmethoden in vergelijking met de Aspergillus niger-methode. Versl. Landbouwk. Onderz. No. 67.10.

Henkens, Ch. H. and Smilde, K. W., 1966. Evaluation of glassy frits as micronutrient fertilizers. I. Copper and molybdenum frits. Neth. J. Agr. Sci., 14: 165-177.

Henkens, Ch. H., Smilde, K. W. en Luit, B. van, 1965. Vergelijking van de waarde van koperslakkenbloem en kopersulfaat als kopermeststoffen op bouwland. Rappt. Inst. Bodemvruchtbaarheid, 14.

Hey, E. und Knabe, O., 1964. Zur Düngung von Niedermoorböden mit Mikronährstoffen. Z. Landeskultur, $4: 277-295$.

Kannenberg, H., 1959. Kornqualität-Spritzung oder Bodendüngung mit Kupfer. Landwirtschaftsblatt Weser-Ems, 8 (Febr.).

Millikan, C. R., 1961. Plant varieties and species in relation to the occurrence of deficiencies and excesses of certain nutrient elements. J. Australian Inst. Agr. Sci., $27: 220-233$.

Mitchell, R. L., Reith, J. W. S. and Johnston, I. M., 1957. Soil copper status and plant uptake. In: Plant analysis and fertilizer problems. I.R.H.O., Paris, pp. 249-259.

Mulder, E. G., 1938. Over de betekenis van koper voor de groei van planten en micro-organismen. Thesis, Wageningen.

Mulqueen, J., Walshe, M. J. and Fleming, G. A., 1961. Copper deficiency on Irish blanket peat. Sci. Proc. Roy. Dublin Soc., Ser. B, $1: 25-35$.

Nelson, L. G., Berger, K. C. and Andries, H. J., 1956. Copper requirements and deficiency symptoms of a number of field and vegetable crops. Soil Sci. Soc. Am. Proc., 20:69-72.

Piper, C. S., 1940. The symptoms and diagnosis of minor element defíciencies in agricultural and horticultural crops. II. Copper, zinc, molybdenum. Empire J. Exptl. Agr., 8: 199-206.

Piper, C. S., 1942. Investigations on copper deficiency in plants. J. Agr. Sci., 32: 143-178.

Piper, C. S. and Walkley, A., 1943. Copper, zinc and manganese in some plants of agricultural interest. J. Counc. Sci. Indust. Res. Austr., 16: 217-234.

Pizer, N. H., Caldwell, T. H., Burgess, G. R. and Jones, J. L. O., 1966. Investigations into copper deficiency in crops in East Anglia. J. Agr. Sci., 66: 303-314.

Rademacher, B., 1940. Über die Veränderungen des Kupfergehaltes, den Verlauf der Kupferaufnahme und den Kupferentzug beim Hafer. Z. Pflanzenernähr., Düng., Bodenk., 19(64) : 80-108.

Reith, J. W. S. and Mitchell, R. L., 1964. The effect of soil treatment on trace element uptake by plants. In: Plant analysis and fertilizer problems. 4, pp. 241-254.

Scharrer, K. und Schaumlöffel, E., 1960. Über die Kupferaufnahme durch Sommergetreide auf Kupfermangelböden. Z. Pflanzenernähr., Düng., Bodenk., 89 : 1-17.

Vose, P. B., 1963. Varietal differences in plant nutrition. Herbage Abstr., $33: 1-13$. 